\title{
Single OTRA Based Analog Multiplier and Its Applications
}

\author{
Rajeshwari Pandey, ${ }^{1}$ Neeta Pandey, ${ }^{1}$ B. Sriram, ${ }^{1}$ and Sajal K. Paul ${ }^{2}$ \\ ${ }^{1}$ Department of Electronics and Communication Engineering, Delhi Technological University, Delhi 110042, India \\ ${ }^{2}$ Department of Electronics Engineering, Indian School of Mines, Dhanbad 826004, India
}

Correspondence should be addressed to Neeta Pandey, n66pandey@rediffmail.com

Received 30 August 2012; Accepted 2 October 2012

Academic Editors: H. A. Alzaher and E. Tlelo-Cuautle

Copyright (C 2012 Rajeshwari Pandey et al. This is an open access article distributed under the Creative Commons Attribution License, which permits unrestricted use, distribution, and reproduction in any medium, provided the original work is properly cited.

This paper presents an analog multiplier using single operational transresistance amplifier (OTRA). The proposed circuit is suitable for integration as it does not use any external passive component. It can be used as a four-quadrant multiplier. Theoretical propositions are verified through PSPICE simulations using $0.5 \mu \mathrm{m}$ CMOS parameters provided by MOSIS (AGILENT). The simulation results are in close agreement with theoretical predictions. The workability of the proposed multiplier is also tested through two applications, namely, a squarer and an amplitude modulator.

\section{Introduction}

Analog multipliers find extensive application in the field of telecommunication, control, instrumentation, measurement, and signal processing [1]. A number of circuits are reported in literature relating to analog multipliers [1-12]. Circuits presented in [2-7] are based on Gilbert multiplier [12] and are suitable for CMOS integrated technology. The other class of the circuits is implemented using active analog blocks such as operational transconductance amplifier [1], differential difference current conveyors [8], current feedback amplifiers [9], current-controlled current conveyor [10], and current difference buffered amplifier [11].

Recently the OTRA has emerged as an alternate analog building block [13-26] which inherits all the advantages of current mode techniques. The OTRA is a high gain current input voltage output device. The input terminals of OTRA are internally grounded, thereby eliminating response limitations due to parasitic capacitances and resistances [13] at the input. Several high performance CMOS OTRA topologies have been proposed in the literature [13-16]. In the recent past OTRA has been extensively used as an analog building block for realizing a number of analog signal processing [17-21] and generation circuits [22-24]. This paper presents a single OTRA based low voltage analog multiplier which does not use any external passive components and hence is suitable for integration. The proposed circuit can be used as a four quadrant multiplier without any change of topology. The workability of the proposed multiplier is demonstrated through two applications, namely, a squarer and an amplitude modulator.

\section{The Proposed Multiplier Circuit}

2.1. OTRA. OTRA is a three-terminal device, shown symbolically in Figure 1 and its port relations are characterized by the following matrix:

$$
\left[\begin{array}{c}
V_{p} \\
V_{n} \\
V_{O}
\end{array}\right]=\left[\begin{array}{ccc}
0 & 0 & 0 \\
0 & 0 & 0 \\
R_{m} & -R_{m} & 0
\end{array}\right]\left[\begin{array}{c}
I_{p} \\
I_{n} \\
I_{O}
\end{array}\right],
$$

where $R_{m}$ is transresistance gain of OTRA. For ideal operations $R_{m}$ approaches infinity and forces the input currents to be equal. Thus OTRA must be used in a negative feedback configuration.

Figure 2 Shows the CMOS realization of OTRA [15] which consists of the cascaded connection of the modified differential current conveyor (MDCC) [8] and common source amplifier. MDCC performs the current differencing operation and forces the two input terminals to be virtually 


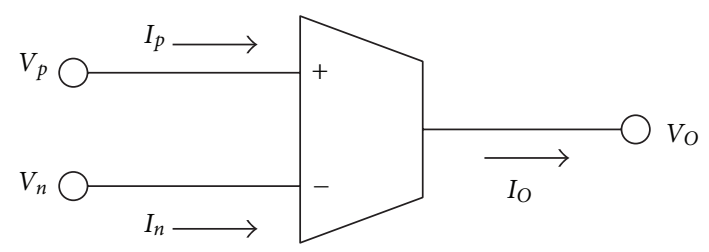

FIgURE 1: OTRA circuit symbol.

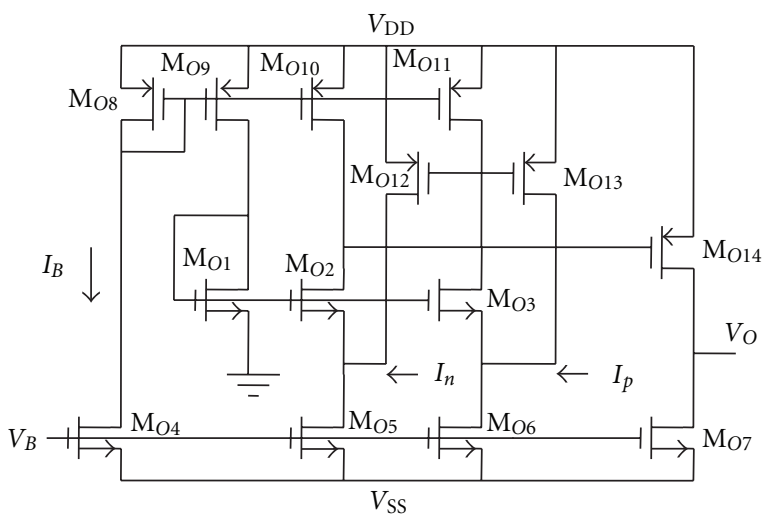

FIGURE 2: Figure 6 CMOS implementation of OTRA [15].

grounded whereas the common source amplifier provides high gain.

2.2. Basic Multiplier Circuit. Figure 3 Shows OTRA based multiplier structure. The transistors $\mathrm{M}_{1}, \mathrm{M}_{2}, \mathrm{M}_{3}$, and $\mathrm{M}_{4}$ are matched transistors and operate in the linear region. In this paper $v_{1}$ and $v_{2}$ represent small signals, whereas $V_{C 1}$, $V_{C 2}$, and $V_{\text {DC }}$ are the bias voltages. OTRA inputs keep the sources of the two transistors $\mathrm{M}_{1}$ and $\mathrm{M}_{2}$ virtually grounded. The drain current for the MOS transistor operating in triode region is given by [27]

$$
I_{D}=k \frac{W}{L}\left(\left(V_{\mathrm{GS}}-V_{T}\right)-\frac{V_{\mathrm{DS}}}{2}\right) V_{\mathrm{DS}}
$$

where $k$ is transconductance; $W$ and $L$ respectively represent the channel width and length of the of the MOSFET. The other terms have their usual meaning.

Using (2) the currents through $p$ and $n$ terminals of OTRA, that is, $i_{p}$ and $i_{n}$, respectively, can be expressed as

$$
\begin{aligned}
i_{p}= & K_{n} \frac{W}{L}\left(\left(\left(V_{\mathrm{DC}}+v_{1}\right)-V_{T}\right)-\frac{v_{2}}{2}\right) v_{2} \\
& +K_{n} \frac{W}{L}\left(\left(V_{C 1}-V_{T}\right)-\frac{v_{o}}{2}\right) v_{o} \\
i_{n}= & K_{n} \frac{W}{L}\left(\left(V_{\mathrm{DC}}-V_{T}\right)-\frac{v_{2}}{2}\right) v_{2} \\
& +K_{n} \frac{W}{L}\left(\left(V_{C 2}-V_{T}\right)-\frac{v_{o}}{2}\right) v_{o} .
\end{aligned}
$$

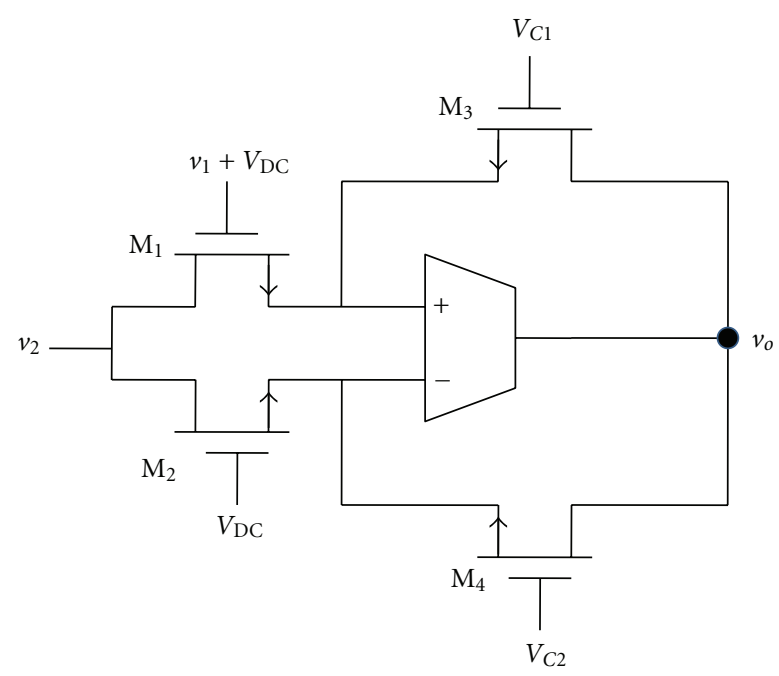

Figure 3: Proposed OTRA based multiplier structure.

As $R_{m}$ approaches infinity the input currents are forced to be equal resulting in

$$
v_{o}=\frac{v_{1} v_{2}}{\left(V_{C 2}-V_{C 1}\right)}=K v_{1} v_{2}
$$

where $K$ is a proportionality constant and is the inverse of difference of gate voltages of $\mathrm{M}_{3}$ and $\mathrm{M}_{4}$.

2.3. Implementation Scheme for Superimposition of a Small Signal on DC Bias. As can be seen from Figure 3 the gate voltage of $\mathrm{M}_{1}$ is $\left(V_{\mathrm{DC}}+v_{1}\right)$ which is a small signal superimposed over a dc bias. This voltage addition can be implemented using a scheme proposed in Figure 4 wherein $v_{x}$ is a small signal voltage and $V_{C}$ is a bias voltage.

If $\mathrm{M}_{P 1}$ and $\mathrm{M}_{P 2}$ are matched transistors and are operating in saturation then their drain currents will be equal resulting in

$$
\frac{1}{2} K_{p} \frac{W}{L}\left(\left(v-V_{C}\right)-V_{t p}\right)^{2}=\frac{1}{2} K_{p} \frac{W}{L}\left(\left(v_{x}-v\right)-V_{t p}\right)^{2},
$$

which gives

$$
v=\frac{\left(V_{C}+v_{x}\right)}{2}
$$

The voltage given by (7) can be used as the gate voltage for transistor $M_{1}$ of Figure 3. Similarly gate voltage for transistor $\mathrm{M}_{2}$ can be obtained from (7) by making $v_{x}=0$. Substituting these values of gate voltages in (5) the output of the multiplier gets modified to

$$
v_{o}=K^{\prime} v_{1} v_{2}, \quad \text { where } K^{\prime}=\frac{K}{2} .
$$

2.4. The Proposed MOS Based Multiplier Structure. The complete MOS based multiplier structure is depicted in Figure 5 which incorporates the voltage addition scheme of Figure 4. 


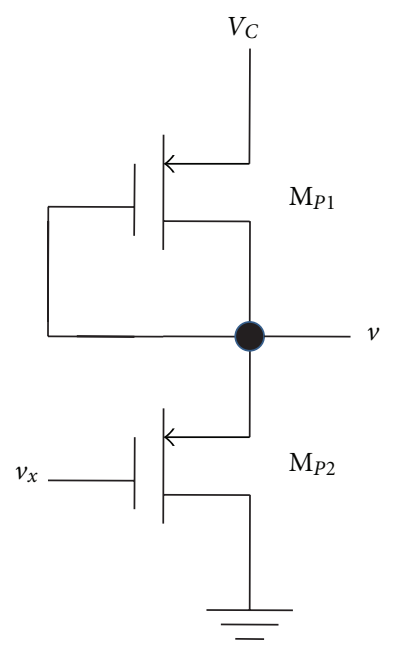

FIGURE 4: Scheme for implementing an ac superimposed on dc bias.

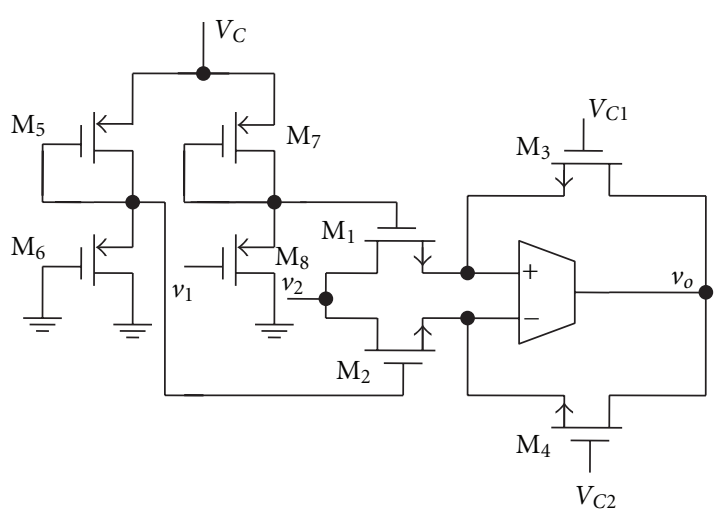

FIGURE 5: Complete multiplier circuit.

As the transistors $\mathrm{M}_{1}, \mathrm{M}_{2}, \mathrm{M}_{3}$, and $\mathrm{M}_{4}$ need to operate in the triode region for proper operation of the multiplier the following conditions should be satisfied:

$$
\begin{gathered}
\left(\frac{\left(V_{C}+v_{1}\right)}{2}-V_{t n}\right)>v_{2}, \\
\left(\left(\frac{V_{C}}{2}\right)-V_{t n}\right)>v_{2}, \\
\left(V_{C 1}-V_{t n}\right)>v_{o}, \\
\left(V_{C 2}-V_{t n}\right)>v_{o} .
\end{gathered}
$$

Now using (7) along with (9) the conditions for input signals $v_{1}$ and $v_{2}$ can be computed as

$$
\begin{gathered}
V_{t p}<v_{1}<\left(V_{C}+2 V_{t p}\right), \\
v_{2}<\frac{\left(V_{C}+v_{1}\right)}{2}-V_{t n} .
\end{gathered}
$$

These equations suggest that the dynamic input range of the multiplier is controlled by $V_{C}$.

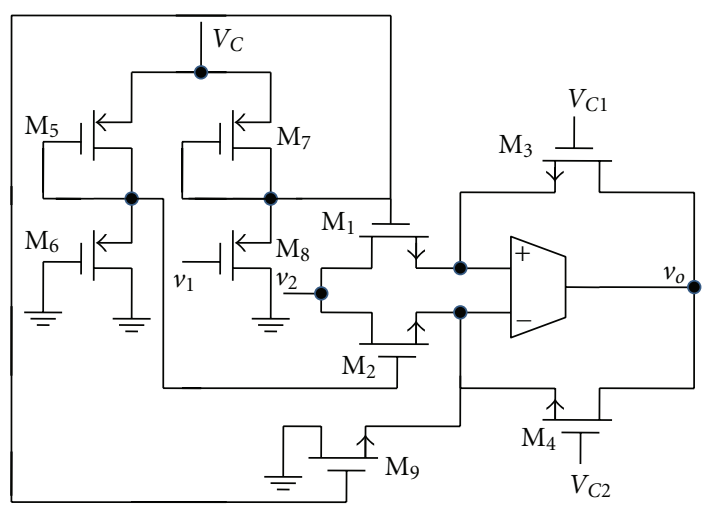

Figure 6: Complete multiplier circuit with $C_{\mathrm{gs}}$ compensation of transistor $\mathrm{M}_{1}$.

\section{Nonideal Analysis}

In this section the effect of finite transresistance gain of OTRA on multiplier is considered and compensation is employed for high frequency applications. Ideally the transresistance gain $R_{m}$ is assumed to approach infinity. However, practically $R_{m}$ is a frequency dependent finite value [13]. Considering a single pole model for the transresistance gain, $R_{m}$ can be expressed as

$$
R_{m}(s)=\left(\frac{R_{0}}{1+s / \omega_{0}}\right)
$$

For high frequency applications the transresistance gain $R_{m}(s)$ reduces to

$$
R_{m}(s) \approx\left(\frac{1}{s C_{p}}\right), \quad \text { where } C_{p}=\frac{1}{R_{0} \omega_{0}} .
$$

For high frequency applications the effect of transistor capacitances needs to be considered. Taking this effect into account the currents $i_{p}$ given by (3) modifies to

$$
\begin{aligned}
i_{p}= & K_{n} \frac{W}{L}\left(\left(\left(V_{\mathrm{DC}}+v_{1}\right)-V_{T}\right)-\frac{v_{2}}{2}\right) v_{2} \\
& +K_{n} \frac{W}{L}\left(\left(V_{C 1}-V_{T}\right)-\frac{v_{o}}{2}\right) v_{o}+v_{1} s C_{\mathrm{gs} 1},
\end{aligned}
$$

where $C_{g s 1}$ is the gate to source capacitance of $\mathrm{M}_{1}$; however, the current $i_{n}$ remains the same as (4). The effect of $C_{\mathrm{gs} 1}$ can be compensated by adding a MOSFET $\mathrm{M}_{9}$, operating in triode region, at the inverting terminal of OTRA as shown in Figure 6. The effective gate to source capacitance of $\mathrm{M}_{9}$ should be equal to $C_{\mathrm{gs} 1}$. This would result in $i_{n}$ as

$$
\begin{aligned}
i_{n}= & K_{n} \frac{W}{L}\left(\left(V_{\mathrm{DC}}-V_{T}\right)-\frac{v_{2}}{2}\right) v_{2} \\
& +K_{n} \frac{W}{L}\left(\left(V_{C 2}-V_{T}\right)-\frac{v_{o}}{2}\right) v_{o}+v_{1} s C_{\mathrm{gs} 1} .
\end{aligned}
$$

The third term in (14) results due to gate to source capacitance of $\mathrm{M}_{9}$. 
TABLE 1: Aspect ratio of the transistors in OTRA circuit.

\begin{tabular}{lc}
\hline Transistor & $W(\mu \mathrm{m}) / L(\mu \mathrm{m})$ \\
\hline $\mathrm{M}_{O 1}-\mathrm{M}_{O 3}$ & $100 / 2.5$ \\
$\mathrm{M}_{O 4}$ & $10 / 2.5$ \\
$\mathrm{M}_{O 5}, \mathrm{M}_{O 6}$ & $30 / 2.5$ \\
$\mathrm{M}_{O 7}$ & $10 / 2.5$ \\
$\mathrm{M}_{O 8}-\mathrm{M}_{O 11}$ & $50 / 2.5$ \\
$\mathrm{M}_{O 12}, \mathrm{M}_{O 13}$ & $100 / 2.5$ \\
$\mathrm{M}_{O 14}$ & $50 / 0.5$ \\
\hline
\end{tabular}

Substituting (12), (13), and (14) in (1), $v_{o}$, the output of multiplier can be evaluated as

$$
v_{o}=\frac{v_{1} v_{2} /\left(V_{C 2}-V_{C 1}\right)}{1+s C_{p} /\left\{K_{n}(W / L)\left(V_{C 2}-V_{C 1}\right)\right\}} .
$$

And hence the $3 \mathrm{~dB}$ bandwidth of the multiplier can be expressed as

$$
\frac{K_{n}(W / L)\left(V_{C 2}-V_{C 1}\right)}{C_{p}}
$$

\section{Simulation Results}

The performance of the proposed multiplier of Figure 5 is verified through SPICE simulation using $0.5 \mu \mathrm{m}$ CMOS process parameters provided by MOSIS (AGILENT). CMOS implementation of the OTRA [15] shown in Figure 2 is used and supply voltages are taken as $\pm 1.5 \mathrm{~V}$. Aspect ratios used for different transistors of OTRA are the same as in [15] and are given in Table 1 . All the transistors $\mathrm{M}_{1}-\mathrm{M}_{8}$ were used with equal aspect ratios having $W / L=1 \mu / 0.5 \mu$. Control voltage is taken as $V_{C}=2 \mathrm{~V}, V_{C 1}=1 \mathrm{~V}$, and $V_{C 2}=1.25 \mathrm{~V}$.

Figure 7 depicts the dc transfer characteristics of the proposed multiplier. The transfer curve $v_{o}$ versus $v_{1}$, with $v_{2}$ kept constant at $250 \mathrm{mV}$, is shown in Figure 7(a). It is observed that $v_{o}$ varies almost linearly with $v_{1}$. The nonlinearity curve representing maximum percent deviation of the ideal transfer characteristic as a function of input voltage $v_{1}$ is shown in Figure 7(b). It is observed that the maximum nonlinearity over the entire input range does not exceed $2.05 \%$. In Figure 7 (c) $v_{o}$ is plotted with respect to $v_{1}$ for different values of $v_{2}$. Voltage $v_{1}$ is swept from $-300 \mathrm{mV}$ to $300 \mathrm{mV}$ while $v_{2}$ is varied from $-150 \mathrm{mV}$ to $150 \mathrm{mV}$ in steps of $50 \mathrm{mV}$. It shows that the proposed circuit is a fourquadrant multiplier.

The frequency response of the proposed multiplier is shown in Figure 8 for which $v_{1}$ is kept constant at $200 \mathrm{mV}$ whereas $v_{2}$ is taken as an ac source having amplitude $250 \mathrm{mV}$. The $3 \mathrm{~dB}$ bandwidth is found to be $8 \mathrm{MHz}$.

Figure 9 shows the total harmonic distortion (THD) as a function of input signal amplitude when a constant dc voltage $(250 \mathrm{mV})$ is applied to $v_{2}$ while a $1 \mathrm{KHz}$ sinusoidal signal is applied to $v_{1}$ with varying amplitude. It can be seen that the maximum THD remains under $0.2 \%$ for the entire input range. Total power consumption of the proposed multiplier is $0.83 \mathrm{mw}$ when $v_{1}=v_{2}=0 \mathrm{~V}, V_{C}=2 \mathrm{~V}, V_{C 1}=$ $1 \mathrm{~V}$, and $V_{\mathrm{C} 2}=1.25 \mathrm{~V}$.

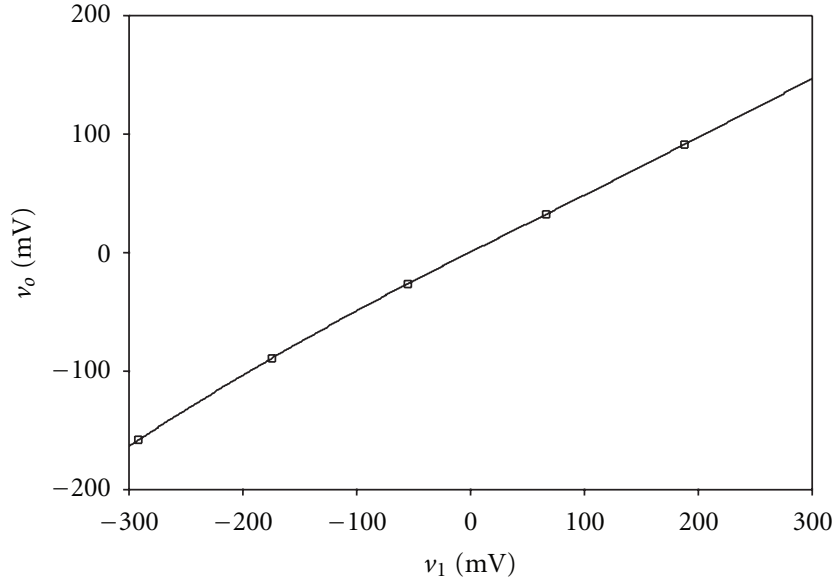

(a) $v_{0}$ versus $v_{1}$ with $v_{2}=250 \mathrm{mV}$

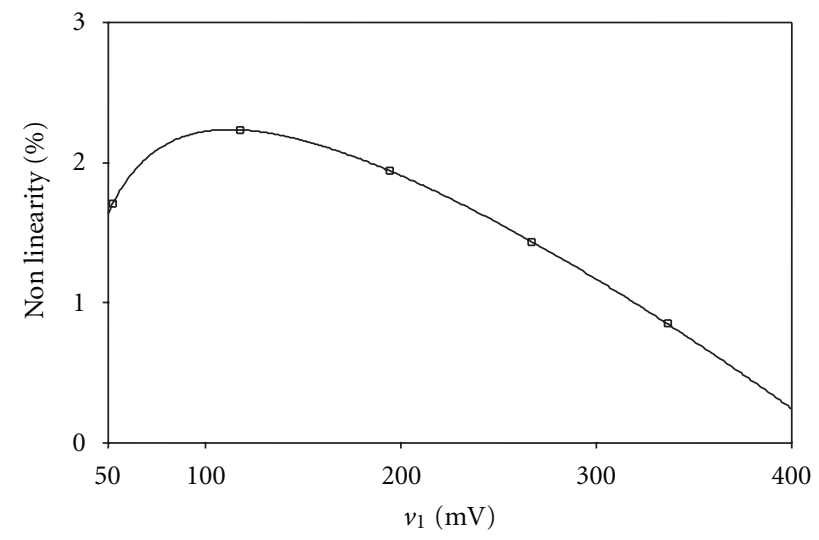

(b) Nonlinearity curve with $v_{2}=250 \mathrm{mV}$

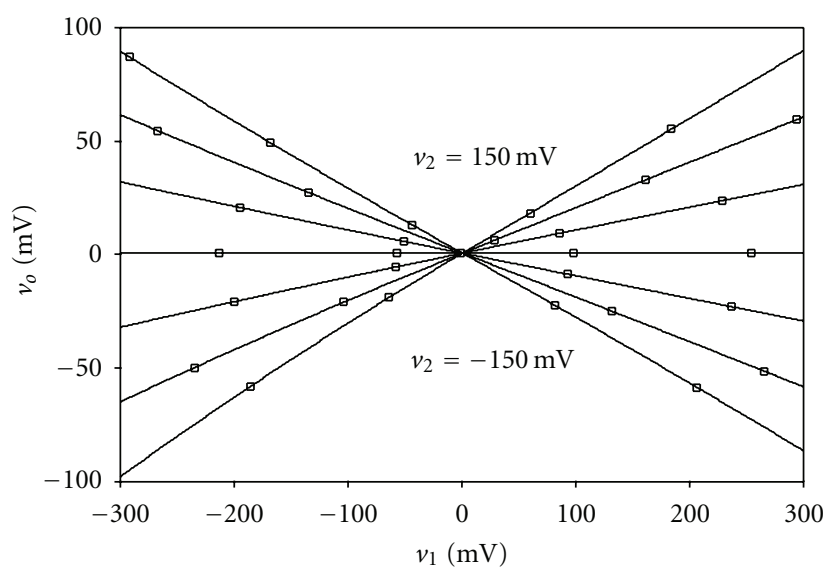

(c) $v_{o}$ versus $v_{1}$ when $v_{2}$ is varied from $-150 \mathrm{mV}$ to $150 \mathrm{mV}$

FIGURE 7: DC transfer characteristic.

\section{Applications}

5.1. Squarer. The proposed multiplier can be used as a squarer circuit if $v_{1}=v_{2}=v_{\text {in }}$. The output of the multiplier is given by

$$
v_{o}=K^{\prime} v_{\mathrm{in}}^{2} .
$$




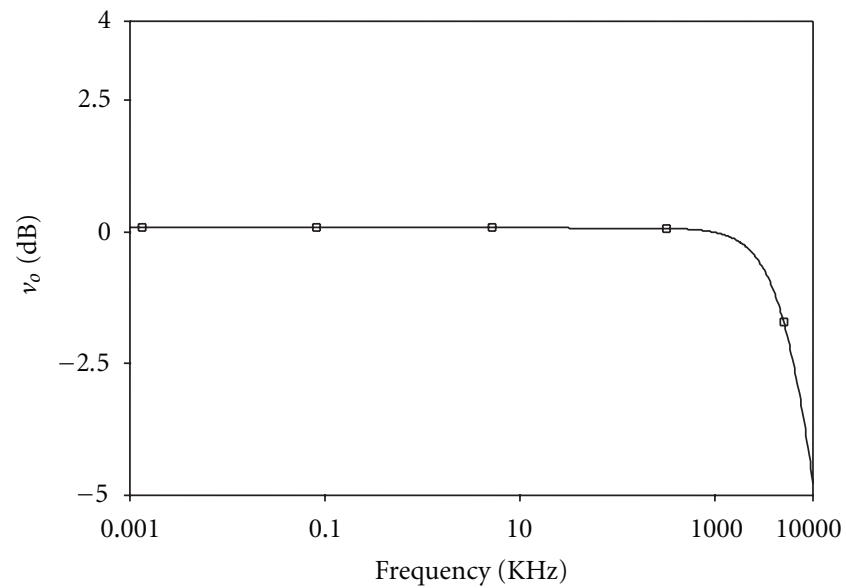

FIGURE 8: AC characteristic of the proposed multiplier.

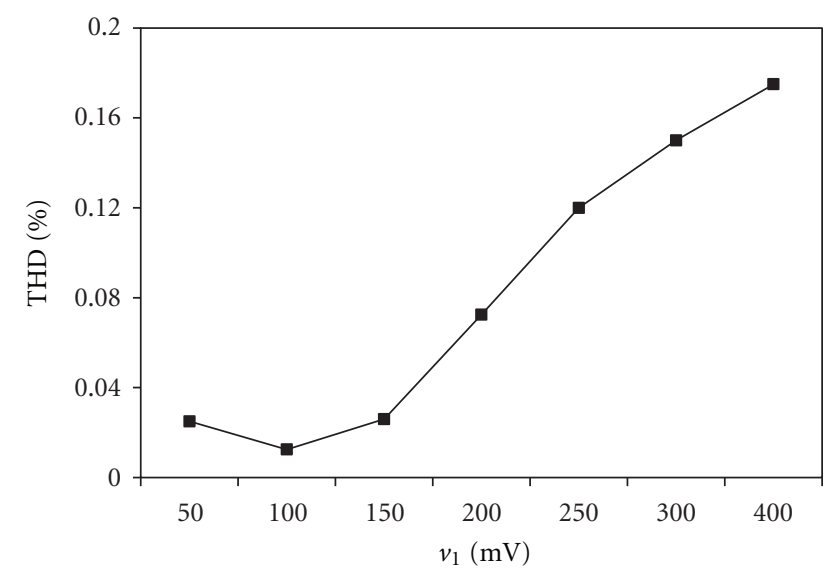

FIGURE 9: THD versus input signal amplitude.

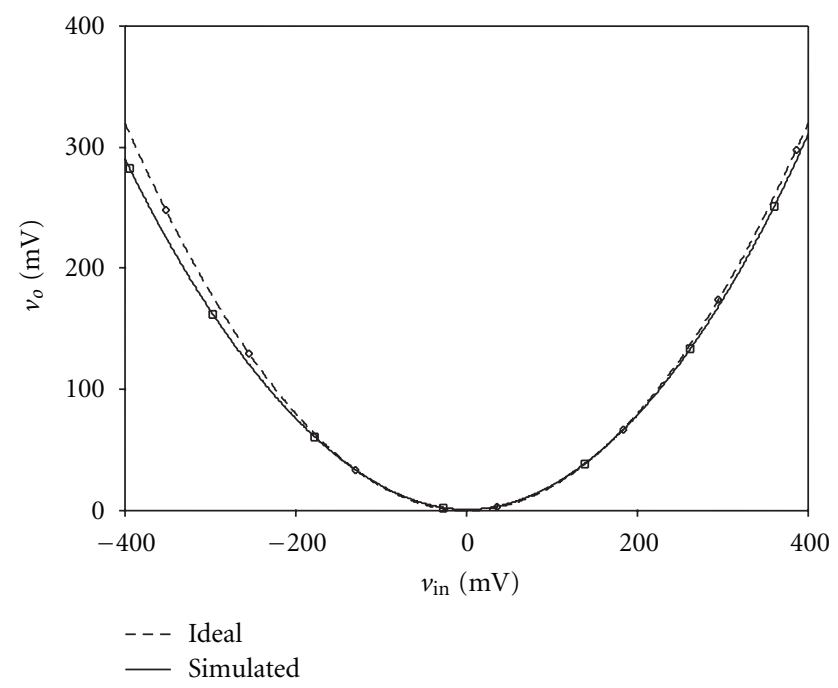

FIGURE 10: Square transfer characteristics.

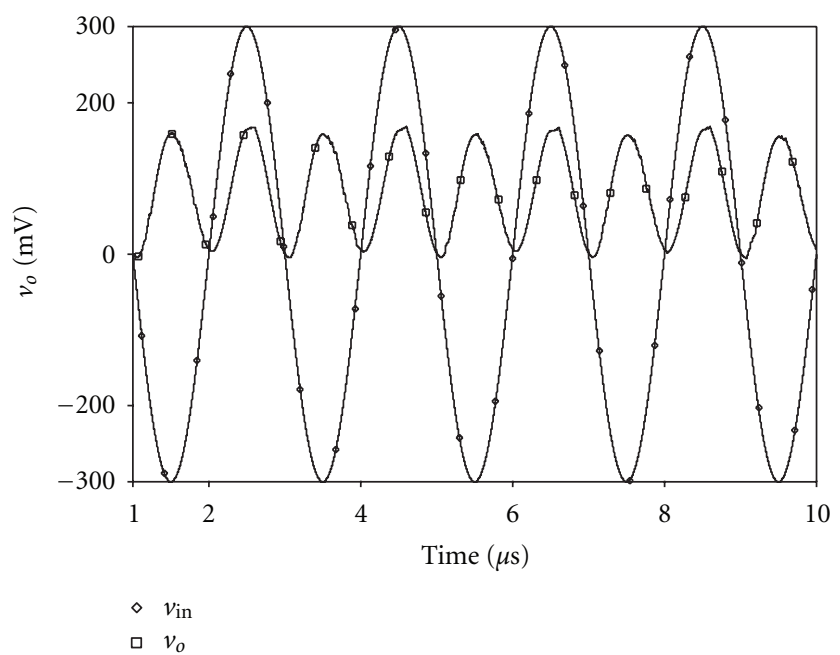

(a) Time domain output of the squarer

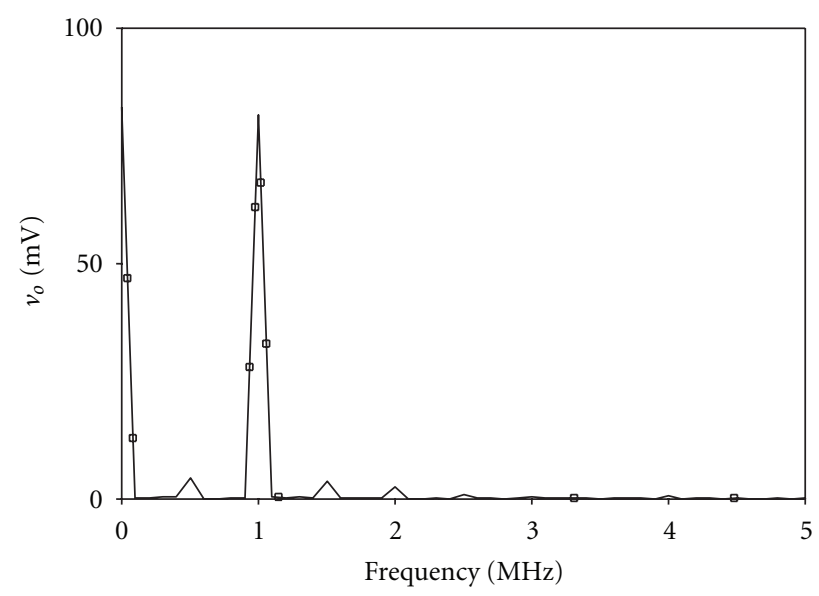

(b) Spectrum of squared sine wave

FIgURE 11: Output of the squarer.

Figure 10 shows the square transfer characteristics wherein $v_{\text {in }}$ is varied from $-400 \mathrm{mV}$ to $400 \mathrm{mV}$.

The observed output of the squarer is shown in Figure 11. The input signal is taken as a $300 \mathrm{mV}, 500 \mathrm{KHz}$ sinusoid. The squared output is shown in Figure 11(a) and the spectrum of the squared output is shown in Figure 11(b).

5.2. Amplitude Modulator. The proposed multiplier, being a four-quadrant multiplier, can be used as an amplitude modulator (AM). A $5 \mathrm{KHz}$ signal with $200 \mathrm{mV}$ amplitude is multiplied by $250 \mathrm{mV}, 50 \mathrm{KHz}$ signal. Figure 12 shows the output of the proposed multiplier confirming the modulation function. The time domain response of the multiplier is shown in Figures 12(a) and 12(b) displays the frequency spectrum.

\section{Conclusion}

A single OTRA based analog multiplier is proposed which can be used as a four-quadrant multiplier also. The circuit does not require any passive element thus making it suitable 


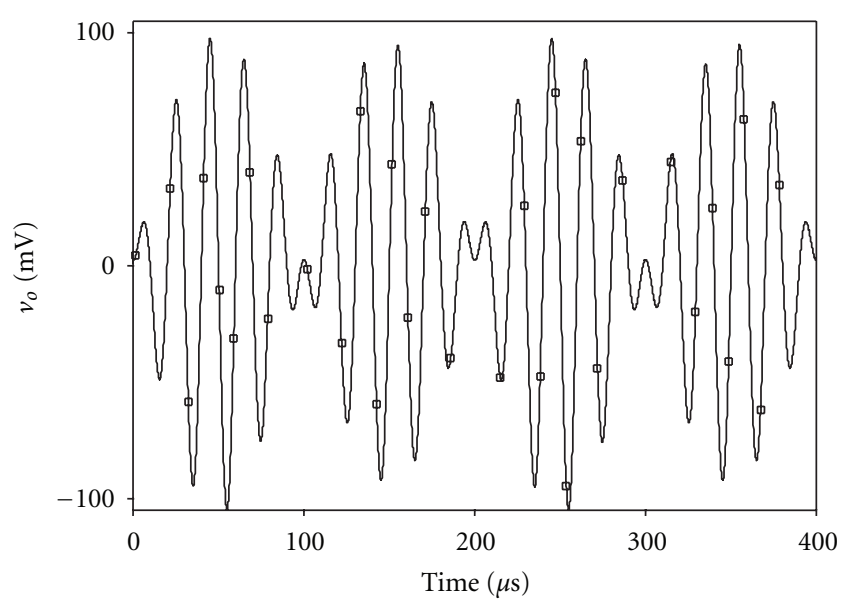

(a) Time domain response

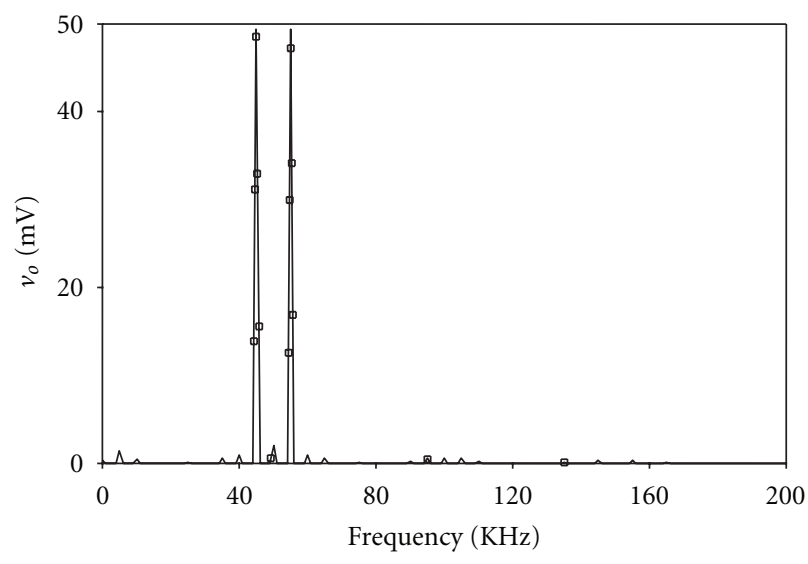

(b) Frequency spectrum

FIGURE 12: Multiplication of two sinusoids.

for integration. Its application as a squarer and an amplitude modulator is also discussed. Theoretical propositions are verified through PSPICE simulations using $0.5 \mu \mathrm{m}$ CMOS parameters provided by MOSIS (AGILENT). Various performance parameters are analyzed through simulations and are found in close agreement to theoretical predictions.

\section{References}

[1] K. Kaewdang, C. Fongsamut, and W. Surakampontorn, "A wide-band current-mode OTA-based analog multiplierdivider," in Proceedings of the IEEE International Symposium on Circuits and Systems (ISCAS '03), vol. 1, pp. I349-I352, May 2003.

[2] S. I. Liu and D. J. Wei, "Analogue squarer and multiplier based on MOS square-law characteristic," Electronics Letters, vol. 32, no. 6, pp. 541-542, 1996.

[3] S. I. Liu and C. C. Chang, "Low-voltage CMOS four-quadrant multiplier based on square-difference identity," IEE Proceedings Circuits, Devices and Systems, vol. 143, pp. 174-176, 1996.

[4] G. Weixin, C. Hongyi, and E. Seevinck, "Quadratic-translinear CMOS multiplier-divider circuit," Electronics Letters, vol. 33, no. 10, pp. 860-861, 1997.
[5] I. Baturone, S. Sanchez-Solano, and J. L. Huertas, "A CMOS current-mode multiplier/divider circuit," in Proceedings of the IEEE International Symposium on Circuits and Systems (ISCAS '98), pp. 520-523, June 1998.

[6] A. Demosthenous and M. Panovic, "Low-voltage MOS linear transconductor/squarer and four-quadrant multiplier for ana$\log$ VLSI," IEEE Transactions on Circuits and Systems I, vol. 52, no. 9, pp. 1721-1731, 2005.

[7] C. Chen and Z. Li, "A low-power CMOS analog multiplier," IEEE Transactions on Circuits and Systems II, vol. 53, no. 2, pp. 100-104, 2006.

[8] H. O. Elwan and A. M. Soliman, "CMOS differential current conveyors and applications for analog VLSI," Analog Integrated Circuits and Signal Processing, vol. 11, no. 1, pp. 35-45, 1996.

[9] S. I. Liu and J. J. Chen, "Realisation of analogue divider using current feedback amplifiers," IEE Proceedings Circuits, Devices and Systems, vol. 142, no. 1, pp. 45-48, 1995.

[10] M. T. Abuelma'atti and M. A. Al-Qahtani, "A currentmode current-controlled current-conveyor-based analogue multiplier/divider," International Journal of Electronics, vol. 85, no. 1, pp. 71-77, 1998.

[11] A. U. Keskin, "A four quadrant analog multiplier employing single CDBA," Analog Integrated Circuits and Signal Processing, vol. 40, no. 1, pp. 99-101, 2004.

[12] B. Gibert, "A precision four-quadrant multiplier with subnanosecond response," The IEEE Journal of Solid-State Circuits, vol. 3, no. 6, pp. 353-365, 1968.

[13] J. J. Chen, H. W. Tsao, and C. C. Chen, "Operational transresistance amplifier using CMOS technology," Electronics Letters, vol. 28, no. 22, pp. 2087-2088, 1992.

[14] K. N. Salama and A. M. Soliman, "CMOS operational transresistance amplifier for analog signal processing," Microelectronics Journal, vol. 30, no. 3, pp. 235-245, 1999.

[15] H. Mostafa and A. M. Soliman, "A modified CMOS realization of the operational transresistance amplifier (OTRA)," Frequenz, vol. 60, no. 3-4, pp. 70-76, 2006.

[16] A. K. Kafrawy and A. M. Soliman, "A modified CMOS differential operational transresistance amplifier (OTRA)," International Journal of Electronics and Communications, vol. 63, no. 12, pp. 1067-1071, 2009.

[17] K. N. S. Ahmed and A. M. Soliman, "Active RC applications of the operational transresistance amplifier," Frequenz, vol. 54, no. 7-8, pp. 171-176, 2000.

[18] S. Kılınc and U. Çam, "Cascadable allpass and notch filters employing single operational transresistance amplifier," Computers and Electrical Engineering, vol. 31, no. 6, pp. 391-401, 2005.

[19] S. Kılınc, A. U. Keskin, and U. Çam, "Cascadable voltage-mode multifunction biquad employing single OTRA," Frequenz, vol. 61, no. 3-4, pp. 84-86, 2007.

[20] S. Kilinc, K. N. Salama, and U. Cam, "Realization of fully controllable negative inductance with single operational transresistance amplifier," Circuits, Systems, and Signal Processing, vol. 25, no. 1, pp. 47-57, 2006.

[21] U. Çam, F. Kaçar, O. Cicekoglu, H. Kuntman, and A. Kuntman, "Novel two OTRA-based grounded immitance simulator topologies," Analog Integrated Circuits and Signal Processing, vol. 39, no. 2, pp. 169-175, 2004.

[22] K. N. Salama and A. M. Soliman, "Novel oscillators using the operational transresistance amplifier," Microelectronics Journal, vol. 31, no. 1, pp. 39-47, 2000.

[23] U. Çam, "A novel single-resistance-controlled sinusoidal oscillator employing single operational transresistance amplifier," 
Analog Integrated Circuits and Signal Processing, vol. 32, no. 2, pp. 183-186, 2002.

[24] R. Pandey, N. Pandey, M. Bothra, and S. K. Paul, "Operational transresistance amplifier-based multiphase sinusoidal oscillators," Journal of Electrical and Computer Engineering, vol. 2011, Article ID 586853, 8 pages, 2011.

[25] C. Sanchez-Lopez, E. Tlelo-Cuautle, and E. Martinez-Romero, "Symbolic analysis of OTRAs-based circuits," Journal of Applied Research and Technology, vol. 9, no. 1, pp. 69-80, 2011.

[26] C. Sánchez-López, F. V. Fernández, and E. Tlelo-Cuautle, "Generalized admittance matrix models of OTRAs and COAs," Microelectronics Journal, vol. 41, no. 8, pp. 502-505, 2010.

[27] A. S. Sedra and K. C. Smith, Microelectronic Circuits, Oxford University Press, New York, NY, USA, 2004. 

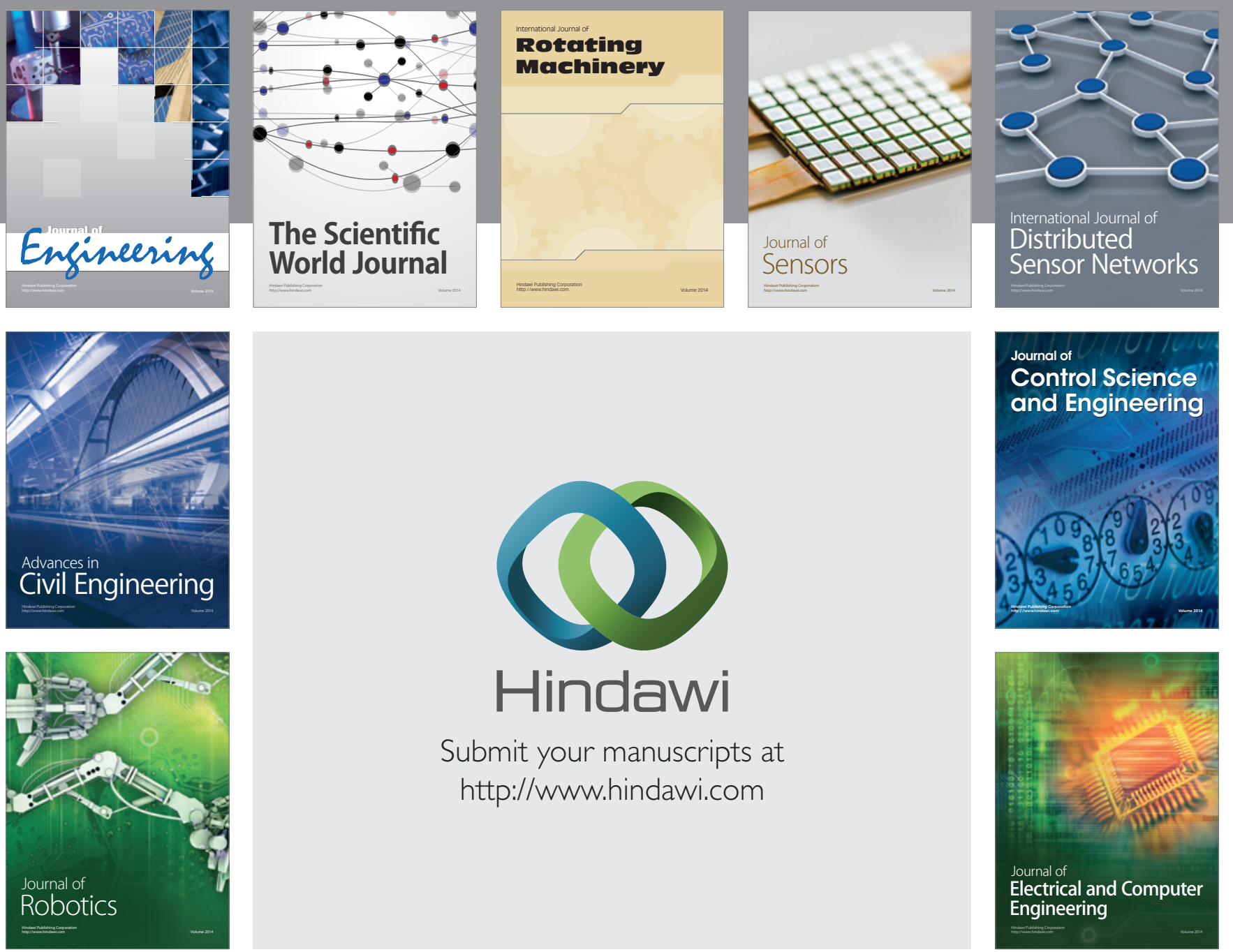

Submit your manuscripts at

http://www.hindawi.com
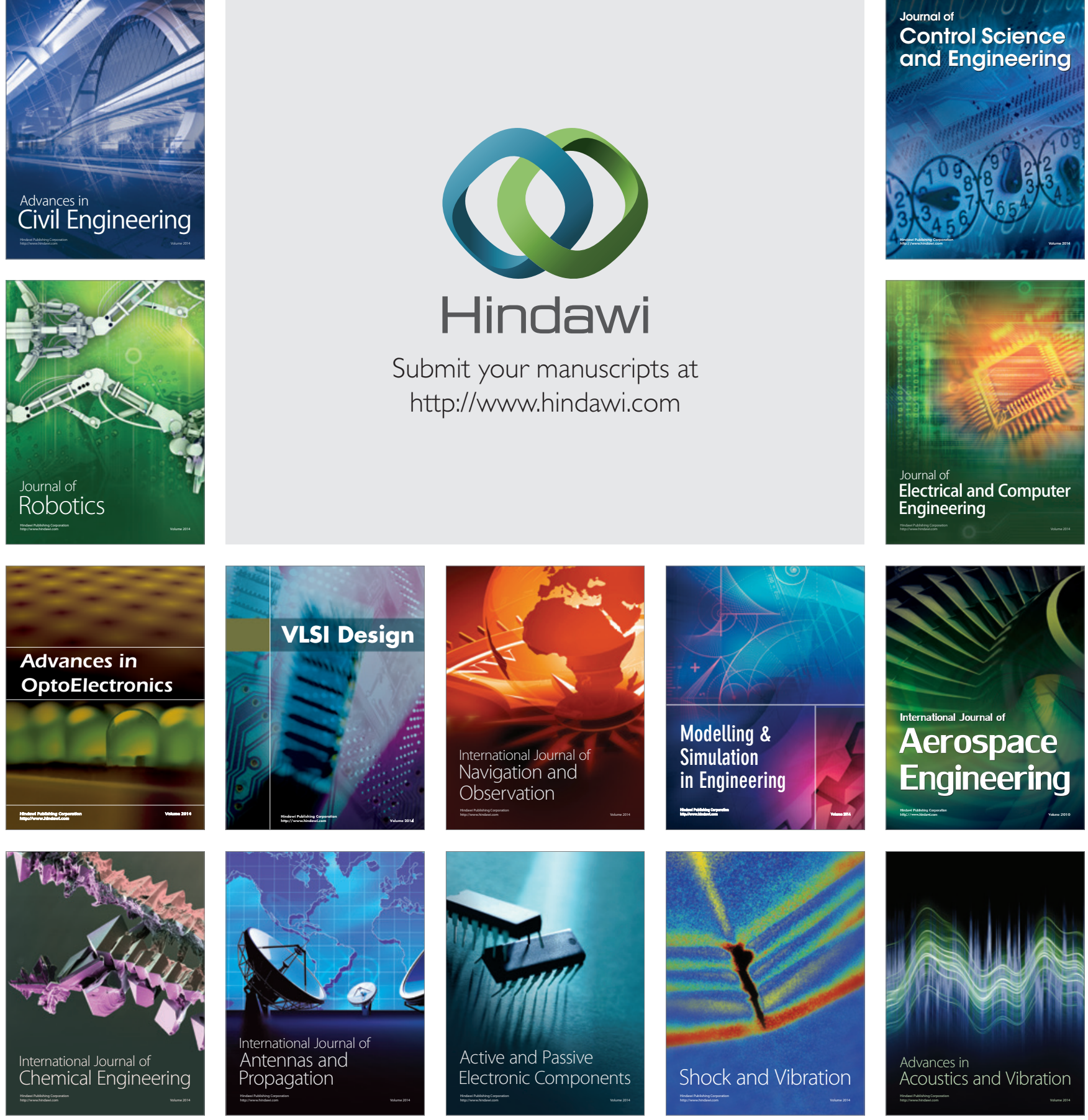